\section{JTI}

JOURNAL OF

TRAUMA AND INJURY

\title{
Pediatric Hand Trauma: An Analysis of 3,432 Pediatric Hand Trauma Cases Over 15 Years
}

\author{
Ki Pyo Sung, M.D., Soo Hyang Lee, M.D., Ph.D. \\ Department of Plastic and Reconstructive Surgery, Ilsan Paik Hospital, Inje University \\ College of Medicine, Goyang, Korea
}

Received: May 10, 2021

Revised: June 29, 2021

Accepted: July 5, 2021

\section{Correspondence to}

Soo Hyang Lee, M.D., Ph.D.

Department of Plastic and Reconstructive Surgery, Ilsan Paik Hospital, Inje Univer-

sity College of Medicine, 170 Juhwa-ro

Ilsanseo-gu, Goyang 10380, Korea

Tel: $+82-31-910-7320$

Fax: +82-31-910-7814

E-mail: shyanglee@naver.com

ORCID: https://orcid.org/0000-0002-

1679-5624

Purpose: Pediatric hand trauma is common and sometimes causes deformity or disability. The incidence and etiologies of hand trauma in children are different from those in adults. This study analyzed the characteristics of pediatric hand trauma cases and patients over a 15 -year period.

Methods: We conducted a retrospective medical record review of 3,432 children (2,265 boys, 1,167 girls, under 18 years of age) with hand injuries from January 2005 to December 2019. We evaluated the sex distribution and injury etiologies. Injuries were classified by type as burns, amputations, crushing injuries, lacerations, extensor and flexor tendon injuries, open and closed fractures, and nerve injuries.

Results: Among the pediatric hand injury patients, males were predominant (1.94:1). Simple lacerations (58.4\%) were the most common injury type, followed by fractures $(22.8 \%)$. Lacerations and burns tended to be common in younger age groups, while tendon injuries, nerve injuries, and crushing injuries were more frequently encountered in older age groups.

Conclusions: Hand trauma prevention strategies should be established considering the frequent trauma etiologies in specific age groups. An awareness of age-specific characteristics of pediatric hand trauma patients will be helpful to prevent hand trauma.

Keywords: Pediatrics; Adolescent; Injuries; Hand

\section{INTRODUCTION}

Pediatric hand trauma is one of the most common injuries reported in emergency departments in the United States [1]. Since hand function is very complex, the treatment of hand trauma requires accurate anatomical knowledge and significant experience 
and expertise.

Because the incidence and etiologies of pediatric and adult hand trauma differ, it is appropriate to establish management strategies based on age group, with a vital focus on the prevention of injuries. Furthermore, permanent functional impairment and mental trauma can be caused by severe pediatric hand trauma [2]. Many treatment-based studies focusing on pediatric trauma have been performed, but relatively few studies have focused on prevention [2-5].

To establish effective prevention strategies, it is necessary to understand the epidemiology of pediatric hand trauma. In this study, the outcomes, age, sex, and etiology of pediatric hand injuries in South Korea were evaluated.

Table 1. Distribution of injury types by sex

\begin{tabular}{|lccc|}
\hline Injury type & $\begin{array}{c}\text { Males } \\
(\mathbf{n}=\mathbf{2 , 2 6 5 )}\end{array}$ & $\begin{array}{c}\text { Females } \\
(\mathbf{n}=\mathbf{1 , 1 6 7 )}\end{array}$ & $\begin{array}{c}\text { Total } \\
(\mathbf{n}=\mathbf{3 , 4 3 2})\end{array}$ \\
\hline Laceration & 1,287 & 717 & 2,004 \\
Closed fracture & 448 & 272 & 720 \\
Open fracture & 53 & 10 & 63 \\
Burn & 168 & 105 & 273 \\
Extensor tendon injury & 111 & 20 & 131 \\
Flexor tendon injury & 36 & 4 & 40 \\
Amputation & 36 & 12 & 48 \\
Nerve injury & 57 & 12 & 69 \\
Crushing injury & 69 & 15 & 84 \\
\hline
\end{tabular}

\section{METHODS}

The study protocol was approved by the Ethics Committee of Inje University Ilsan Paik Hospital (IRB No. 202011-030-001). We conducted a retrospective outpatient record and admission chart review of 1,144 patients with hand injuries from January 2005 to December 2019. Our study included 3,432 children (2,265 boys, 1,167 girls) aged less than 18 years. Six age Groups were established: 0-3 years, $4-6$ years, $7-9$ years, $10-12$ years, $13-15$ years, and 16-18 years (denoted as Groups 1-6, respectively, elsewhere in the study). We compared and analyzed the characteristics of pediatric trauma patients according to age group.

We evaluated outcomes, age, sex, and injury etiology. The injuries were classified by etiology as burns, amputations, crushing injuries, lacerations, extensor and flexor tendon injuries, open and closed fractures, or nerve injuries. Data were analyzed using SPSS (IBM Corp., Armonk, NY, USA). The chi-square test for homogeneity was used to compare the distribution of injury between sex and age groups. Differences were considered statistically significant if the $p$-value was less than 0.05 . Informed consent was obtained from each patient included in the study.

\section{RESULTS}

Among the pediatric patients who presented to the Inje

Table 2. Distribution of injury types by age group

\begin{tabular}{|c|c|c|c|c|c|c|}
\hline Injury type & Group $1(n=1,065)$ & Group $2(n=525)$ & Group $3(n=330)$ & Group $4(n=402)$ & Group $5(n=552)$ & Group $6(n=558)$ \\
\hline Laceration & 684 & 357 & 201 & 204 & 264 & 294 \\
\hline Closed fracture & 171 & 80 & 101 & 132 & 150 & 86 \\
\hline Open fracture & 6 & 4 & 4 & 12 & 18 & 19 \\
\hline Burn & 171 & 64 & 2 & 6 & 18 & 12 \\
\hline Extensor tendon injury & 9 & 11 & 7 & 9 & 48 & 47 \\
\hline Flexor tendon injury & 3 & 1 & 2 & 3 & 12 & 19 \\
\hline Amputation & 9 & 3 & 3 & 11 & 6 & 16 \\
\hline Nerve injury & 6 & 2 & 4 & 12 & 18 & 27 \\
\hline Crushing injury & 6 & 3 & 6 & 13 & 18 & 38 \\
\hline
\end{tabular}

The patients were grouped according to age into Group 1 (0-3 years), Group 2 (4-6 years), Group 3 (7-9 years), Group 4 (10-12 years), Group 5 (13-15 years), and Group 6 (16-18 years). 
University Ilsan Paik Hospital for hand injuries, 2,265 $(66.0 \%)$ were boys and 1,167 (34.0\%) were girls. The ratio of males to females was 1.94:1 (Table 1). There was a statistically significant difference in the distribution of injuries by sex $(p<0.001)$.

An analysis of the distribution of hand injuries by age group revealed that there were 1,065 patients $(31.0 \%)$ in Group 1, 525 patients (15.3\%) in Group 2, 330 patients $(9.6 \%)$ in Group 3, 402 patients (11.7\%) in Group 4, 552 patients (16.1\%) in Group 5, and 558 patients (16.3\%) in Group 6, with Group 1 having the most patients (Table 2). The age groups showed statistically significant differences in the mechanism of trauma $(p<0.001)$.

Among all pediatric hand injury patients, simple lacerations $(58.4 \%)$ were the most common injury type, followed by fractures $(22.8 \%)$. Closed fractures accounted for $92.0 \%$ of all fractures. Simple lacerations were the most common cause of injuries in all age groups, followed by fractures. Lacerations and burns tended to be common in younger age groups, while tendon, nerve, and crushing injuries were more commonly encountered in older age groups (Fig. 1). The distribution of the locations of the lacerations and burns is summarized in Table 3 .

\section{DISCUSSION}

Musculoskeletal system development differs according to age, which is why this study categorized patients into six age groups. Infants and toddlers aged 3 years or less and preschool children aged 4-6 years were classified as separate groups, and children and adolescents aged $7-18$ years were divided into four groups, as children have different characteristics at each stage in terms of maturity.

Group 1, which included infants and toddlers, had the

Table 3. Distribution of the location of lacerations and burns

\begin{tabular}{|llc|}
\hline Injury type & \multicolumn{1}{c}{ Location } & Number of patients \\
\hline Laceration $(n=2,004)$ & Distal phalanx & 661 \\
& Middle phalanx & 381 \\
& Proximal phalanx & 790 \\
& MCP area & 172 \\
Burn $(n=273)$ & Finger & 80 \\
& Hand dorsum & 93 \\
& Palm & 79 \\
& Multiple area & 21 \\
\hline
\end{tabular}

MCP: metacarpophalangeal.

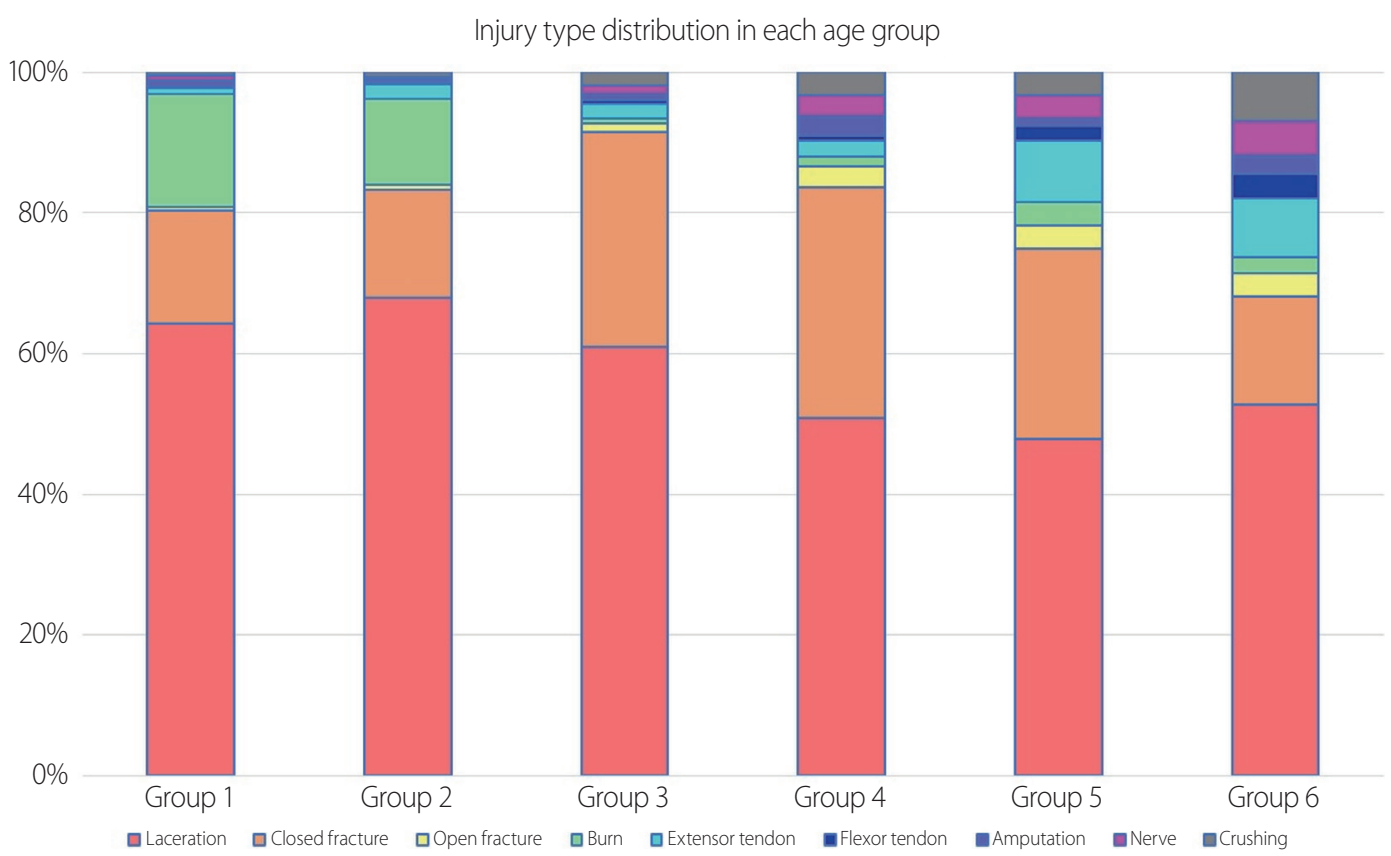

Fig. 1. Lacerations and burns tended to be common in younger age groups, while tendon, nerve, and crushing injuries were more frequently encountered in older age groups. 
highest proportion of hand injuries $(31.0 \%)$. As age increased, the proportion of hand injuries decreased until Group 3, at which point it subsequently increased (Table 2). A previous study also showed that the youngest group ( $0-3$ years) and the oldest group (13-15 years) constituted more than half of all injuries [6]. The incidence of burns was exceptionally high in Group 1. The ratio of burns or lacerations to all types of injuries was relatively low in the older groups, while severe injuries including amputation, crushing injuries, and nerve injuries had the highest proportions in Groups 5 and 6. From a pediatric developmental point of view, this result can be explained by the fact that that infants and toddlers are vulnerable to trauma because of their lack of body balance control and immature intellectual development and learning ability. The frequency of trauma decreases with the development of these functions in late childhood and early adolescence. However, the incidence increases again during adolescence because children's range of behavior expands.

During the study period, there were 3,432 pediatric hand trauma patients, of whom 2,265 (66.0\%) were boys, suggesting that hand trauma is more likely to occur in boys. Our evidence-based result shows a slightly higher male-to-female ratio than a previous study in 344 hand injuries of Korean children [6]. Of particular note, the maleto-female ratio was highest for flexor tendon injuries (9.0), and it was also higher than 3.0 for more severe injuries such as open fractures, amputations, nerve injuries, and crushing injuries. Similar to our findings, a male predominance has also been reported in other countries [7-10].

Regarding the distribution of injury type, there were 2004 simple lacerations (58.4\%), which were the most common injury in all age groups. The laceration injuries generally did not damage bones, ligaments, nerves, or blood vessels, and the patients were discharged after treatment with simple sutures. The proximal phalanx was the most common site of injury (39.4\%), followed by the distal phalanx and middle phalanx. Closed fractures accounted for the majority of all fractures (92.0\%). Among tendon injuries, extensor tendon injuries were 2.3 times more common than flexor injuries.

Crushing injury of the finger by a door is common [11]. It should also be noted that injuries due to outdoor activities are generally more serious than those due to indoor activities [12,13]. Hand injuries occur most frequently at home in all age groups, especially in young children under the age of five [14]. Some studies have reported that children older than 6 years are more likely to suffer from hand injuries in outdoor environments, such as while participating in sports $[8,10]$.

Burns accounted for $8.0 \%$ of hand injuries and were most common in Group 1. Burns on the hand dorsum were most common, but there was no significant difference in the proportion of burns on the fingers and palm. Other studies have also reported that burns occurred more frequently in younger children $[9,15,16]$. There are some specific aspects of pediatric hand burns. First, unlike adult burns, which are often caused by industrial activities, pediatric burns are generally small, superficial scalding burns that take place at home and do not affect deep tissues. Second, the hands of a child continue to grow; therefore, excessive scar tissue formed by severe burns requires multiple surgical procedures throughout their lifespan. For this reason, it is more difficult to obtain good cosmetic and functional results in pediatric burn patients than in adult burn patients. In addition, children are often immature in their physical development, as well as their behavior and intelligence, so it is important for parents and guardians to understand the specific epidemiology of burns to prevent their occurrence [17].

Proper treatment is particularly important for hand injuries, especially burns. Tendon injuries or excessive scar formation caused by burn wounds can induce functional complications in children at a critical developmental time. Therefore, it is recommended that guardians of children be aware of the differences in trauma incidence. Especially for infants and toddlers who cannot pay attention to avoid injuries themselves, sharp materials should be removed from the visual field because preventable simple lacerations account for the largest portion of hand injuries [6]. In addition, because infants have the highest incidence of burns of all ages, efforts should be made to supervise children around stoves, fireplaces, hair irons, and clothes irons [18]. As cooking is the most common cause of burns, parents and guardians should be taught not only to have children leave the kitchen while preparing a meal, but also to prevent children from touching hot meals. In particular, because rice cookers are the major cause of 
hand steam burns in children in Asian countries, parents should keep an eye on their children so that they do not touch the cooker [19]. Frequent educational programs for teachers in nurseries and schools could also help prevent burns in this population.

As age increases, more severe injuries become more common, including fractures, tendon injuries, and amputations. Because crushing injury by a door is a common cause of hand trauma in this age range, safety devices such as finger guard devices and triangular-shaped stoppers can be applied on the hinge side of doors. Magnets installed on the back of a door and opposing wall surface can be an effective way to prevent unintended door closures [11]. Moreover, because outdoor activities such as sports cause more serious trauma to the hand, injury-preventing strategies, including stretching, bracing, or taping, should precede these activities [20]. However, these methods are not fundamental solutions, and because children at this age are intelligent enough to communicate and understand the causes and prevention of trauma, it is imperative to provide a sufficient explanation and familiarization with skills and movement before the activity. Educators must be prepared for various hand injuries, and schools must have emergency kits, as well as a network of emergency contacts with connections to specialized trauma centers or burn wound-care centers.

\section{CONCLUSION}

Children in different age groups have different characteristics, which change as they mature and physically grow. Therefore, the type and frequency of injuries vary by age group. Awareness of the age-specific characteristics of pediatric hand trauma patients will be helpful for the prevention of hand trauma, and preventive strategies should be established considering frequent trauma etiologies in each age group.

\section{CONFLICTS OF INTEREST}

No potential conflict of interest relevant to this article was reported.

\section{INFORMED CONSENT}

Informed consent was obtained from all individual participants included in this study.

\section{REFERENCES}

1. Nofsinger CC, Wolfe SW. Common pediatric hand fractures. Curr Opin Pediatr 2002;14:42-5.

2. Beris AE, Lykissas MG, Korompilias AV, Mitsionis GI, Vekris MD, Kostas-Agnantis IP. Digit and hand replantation. Arch Orthop Trauma Surg 2010;130:1141-7.

3. Ozer K, Kramer W, Gillani S, Williams A, Smith W. Replantation versus revision of amputated fingers in patients air-transported to a level 1 trauma center. J Hand Surg Am 2010;35:936-40.

4. Pike J, Mulpuri K, Metzger M, Ng G, Wells N, Goetz T. Blinded, prospective, randomized clinical trial comparing volar, dorsal, and custom thermoplastic splinting in treatment of acute mallet finger. J Hand Surg Am 2010;35:580-8.

5. Yeo CJ, Sebastin SJ, Chong AK. Fingertip injuries. Singapore Med J 2010;51:78-87.

6. Jeon BJ, Lee JI, Roh SY, Kim JS, Lee DC, Lee KJ. Analysis of 344 hand injuries in a pediatric population. Arch Plast Surg 2016;43:71-6.

7. Shah SS, Rochette LM, Smith GA. Epidemiology of pediatric hand injuries presenting to United States emergency departments, 1990 to 2009. J Trauma Acute Care Surg 2012;72:1688-94.

8. Doraiswamy NV, Baig H. Isolated finger injuries in children--incidence and aetiology. Injury 2000;31:571-3.

9. Ljungberg E, Rosberg HE, Dahlin LB. Hand injuries in young children. J Hand Surg Br 2003;28:376-80.

10. Mahabir RC, Kazemi AR, Cannon WG, Courtemanche DJ. Pediatric hand fractures: a review. Pediatr Emerg Care 2001;17:153-6.

11. Liu WH, Lok J, Lau MS, Hung YW, Wong CW, Tse WL, et al. Mechanism and epidemiology of paediatric finger injuries at Prince of Wales Hospital in Hong Kong. Hong Kong Med J 2015;21:237-42.

12. Chomiak J, Junge A, Peterson L, Dvorak J. Severe injuries in football players. Influencing factors. Am J Sports Med 2000;28(Suppl 5):S58-68.

13. Laver L, Pengas IP, Mei-Dan O. Injuries in extreme sports. J Orthop Surg Res 2017;12:59.

14. Vadivelu R, Dias JJ, Burke FD, Stanton J. Hand injuries in chil- 
dren: a prospective study. J Pediatr Orthop 2006;26:29-35.

15. Fetter-Zarzeka A, Joseph MM. Hand and fingertip injuries in children. Pediatr Emerg Care 2002;18:341-5.

16. Bhende MS, Dandrea LA, Davis HW. Hand injuries in children presenting to a pediatric emergency department. Ann Emerg Med 1993;22:1519-23.

17. Dado DV, Angelats J. Management of burns of the hands in children. Hand Clin 1990;6:711-21.

18. Turner C, Spinks A, McClure R, Nixon J. Community-based interventions for the prevention of burns and scalds in children. Cochrane Database Syst Rev 2004;2004:CD004335.

19. Roh TS, Kim YS, Burm JS, Chung CH, Kim JB, Oh SJ. Rice cooker steam hand burn in the pediatric patient. Plast Reconstr Surg 2000;106:76-80.

20. Williams S, Whatman C, Hume PA, Sheerin K. Kinesio taping in treatment and prevention of sports injuries: a meta-analysis of the evidence for its effectiveness. Sports Med 2012;42:153-64. 